\title{
Non-anesthesiologist administration of propofol for gastrointestinal endoscopy: European Society of Gastrointestinal Endoscopy, European Society of Gastroenterology and Endoscopy Nurses and Associates Guideline - Updated June 2015

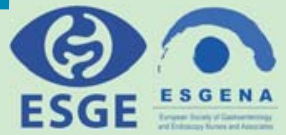

Authors

Institutions
Jean-Marc Dumonceau' ${ }^{1}$, Andrea Riphaus ${ }^{2}$, Florian Schreiber ${ }^{3}$, Peter Vilmann ${ }^{4}$, Ulrike Beilenhoff ${ }^{5}$, Jose R. Aparicio ${ }^{6}$, John J. Vargo ${ }^{7}$, Maria Manolaraki ${ }^{8}$, Caroline Wientjes ${ }^{9}$, István Rácz ${ }^{10}$, Cesare Hassan ${ }^{11}$, Gregorios Paspatis ${ }^{12}$
Bibliography

DOI http://dx.doi.org/

10.1055/s-0034-1393414

Published online: 12.11.2015

Endoscopy 2015; 47: 1175-

1189

(c) Georg Thieme Verlag KG

Stuttgart $\cdot$ New York

ISSN 0013-726X

\section{Corresponding author}

J. M. Dumonceau, MD PhD

Gedyt Endoscopy Center

Beruti 2347 (C1117AAA)

Buenos Aires

Argentina

Fax: + 54-11-52886100

jmdumonceau@hotmail.com

This Guideline is an official statement of the European Society of Gastrointestinal Endoscopy (ESGE) and the European Society of Gastroenterology and Endoscopy Nurses and Associates (ESGENA). It addresses the administration of propofol by non-anesthesiologists for gastrointestinal (GI) endoscopy.

\section{Main Recommendations}

1 We recommend that the type of endoscopic procedure and the patient's American Society of Anesthesiologists (ASA) physical status, age, body mass index, Mallampati's classification, and risk factors for obstructive sleep apnea (OSA) be assessed before each procedure with non-anesthesiologist administration of propofol (NAAP) (strong recommendation, moderate quality evidence).

2 We suggest primary involvement of an anesthesiologist in patients of ASA class $\geq 3$, with a Mallampati's class $\geq 3$ or other conditions that put them at risk of airway obstruction (e.g. pharyngolaryngeal tumors), in patients who chronically receive significant amounts of narcotic analgesics, or in cases where a long-lasting procedure is anticipated (weak recommendation, low quality evidence).

3 We suggest consideration of capnographic monitoring during NAAP in specific situations including high risk patients, intended deep sedation, and long procedures (weak recommendation, high quality evidence).

4 We suggest propofol monotherapy except in particular situations (weak recommendation, high quality evidence).

5 We recommend administering propofol through intermittent bolus infusion or perfusor systems, including target-controlled infusion (TCI), and consideration of patient-controlled sedation
(PCS) in particular situations (strong recommendation, high quality evidence).

6 We suggest that patients listen to self-selected music during upper and lower GI endoscopy procedures (weak recommendation, moderate quality evidence).

7 We do not suggest using pharyngeal anesthesia during propofol sedation for upper GI endoscopy (weak recommendation, moderate quality evidence).

8 We suggest using the post-anesthetic discharge scoring system (PADSS) to determine when patient recovery is sufficient to allow discharge (weak recommendation, low quality evidence). 9 Minimum discharge criteria should be fulfilled before discharging a patient. We recommend that patients who have received combined regimens, and all patients of ASA class $>2$, should upon discharge be accompanied by a responsible person and refrain for 24 hours from driving, drinking alcohol, operating heavy machinery, or engaging in legally binding decisions. Advice should be provided verbally and in written form to the patient, including a 24-hour contact phone number (strong recommendation, low quality evidence).

10 For patients of ASA classes 1-2 who have received low dose propofol monotherapy, a 6-hour limit is suggested (weak recommendation, low quality evidence).

$\begin{array}{ll}\text { Abbreviations } \\ \nabla \\ \text { ACLS } & \text { advanced cardiovascular life support } \\ \text { ASA } & \text { American Society of Anesthesiologists } \\ \text { BIS } & \text { bispectral index } \\ \text { BLS } & \text { basic life support }\end{array}$

BMI

CAPS

CORI

CPAP

EEG body mass index

computer-assisted personalized sedation

Clinical Outcomes Research Initiative continuous positive airway pressure electroencephalogram 


$\begin{array}{ll}\text { EGD } & \text { esophagogastroduodenoscopy } \\ \text { ERCP } & \begin{array}{l}\text { endoscopic retrograde cholangiopancreatography } \\ \text { ESGE }\end{array} \\ \text { European Society of Gastrointestinal Endoscopy } \\ \text { ESGENA } & \begin{array}{l}\text { European Society of Gastroenterology and Endoscopy } \\ \text { Nurses and Associates }\end{array} \\ \text { EUS } & \begin{array}{l}\text { endoscopic ultrasonography } \\ \text { EUS-FNA }\end{array} \\ \text { EUS-guided fine needle aspiration } \\ \text { GI } & \text { gastrointestinal } \\ \text { GRADE } & \text { Grading of Recommendations Assessment, } \\ & \text { Development and Evaluation } \\ \text { NAAP } & \text { non-anesthesiologist administration of propofol } \\ \text { OSA } & \text { obstructive sleep apnea } \\ \text { PADSS } & \text { post-anesthetic discharge scoring system } \\ \text { PCS } & \text { patient-controlled sedation } \\ \text { RCT } & \text { randomized controlled trial } \\ \text { SED } & \text { Sedasys } \\ \text { TCI } & \text { target-controlled infusion }\end{array}$

\section{Introduction}

\section{$\nabla$}

A strong interest in the use of propofol for sedation during gastrointestinal (GI) endoscopy has been demonstrated in all European countries where nationwide surveys have examined sedation regimens used for GI endoscopy [1 -5]; in several countries there has been a tendency for propofol sedation to replace "traditional sedation" based on the administration of benzodiazepines either alone or combined with opioids.

The Guideline on non-anesthesiologist administration of propofol (NAAP) for GI endoscopy published in 2010 by the European Society of Gastrointestinal Endoscopy (ESGE), European Society of Gastroenterology and Endoscopy Nurses and Associates (ESGENA), and the European Society of Anaesthesiology (ESA) aimed to provide a qualified basis for GI endoscopists and endoscopy nurses to provide propofol sedation [6]. New evidence that has become available since then is discussed in the present update and new recommendations are issued. The Guidelines cover the care provided to any patient undergoing GI endoscopy. They are not designed to be rigid and cannot replace clinical judgment; furthermore, their implementation may be subject to domestic regulations or local policy and they should only be used with the agreement of the relevant domestic regulatory authority or local policy maker.

\section{Methods}

The previous version of the Guideline, issued in 2010, was endorsed by three societies, namely the ESGE, the ESGENA, and the ESA; the latter has since retracted its endorsement following long internal discussions [7]. Therefore, this update of the Guideline on NAAP was commissioned and funded by the ESGE and the ESGENA only.

Methods similar to those used in the previous Guideline were employed [8]. A literature search of PubMed/MEDLINE, and searches using the Cochrane Library, EMBASE, and the internet were performed to identify publications since December 2009 on this topic. The search focused on fully published prospective studies, particularly randomized controlled trials (RCTs) and meta-analyses. Retrospective analyses and pilot studies were also included if they addressed topics not covered in the prospective studies.
The Grading of Recommendations Assessment, Development and Evaluation (GRADE) system was adopted to define the strength of recommendation and the quality of evidence [9]. Thereafter, the commissioned authors met once (Vienna, October 2014) and subsequently developed the updated Guideline. The Guideline committee chair (J.M.D.) worked with the subgroup leaders (J.R. A., F.S., G.P., A.R.), who developed draft proposals that were distributed and reviewed electronically.

Literature searches were re-run in February 2015. This timepoint should be the starting point in the search for new evidence for future updates to these Guidelines. In May 2015, a draft prepared by J.M.D. was sent to all group members. As agreement was not reached for the key question about personnel requirement for NAAP, an online survey asking respondents to choose between keeping the 2010 recommendation and changing to a modified recommendation was performed (see point 5.2.1 for details).

After agreement on a final version, the manuscript was sent to all individual ESGE and ESGENA members, and individual ESGE and ESGENA member societies, and was reviewed by two experts selected by the ESGE Governing Board. After incorporation of comments, the manuscript was then sent to the journal Endoscopy for publication. The final wording of the Guideline document was agreed by all commissioned authors.

Evidence statements and recommendations are shown with a green background; key evidence statements and recommendations are in bold. This Guideline was issued in 2015 and will be considered for review in 2019, or sooner if new evidence becomes available. Any updates to the Guideline in the interim period will be noted on the ESGE website: http://www.esge.com/ esge-guidelines.html.

\section{Propofol-based versus traditional sedation}

\section{$\nabla$}

Statement 2010: Compared with traditional sedation, propofol-based sedation presents similar rates of adverse effects, provides higher post-procedure patient satisfaction for most endoscopic procedures, decreases time to sedation, and decreases recovery time (and may therefore decrease discharge time compared with traditional sedation). Propofol-based sedation may also increase the quality of the endoscopic examination. There are no cost-effectiveness data directly comparing specifically NAAP with traditional sedation or monitored anesthesia care for Gl endoscopy. (Evidence level 1+.)

Statement 2015: NAAP is safe. Compared with traditional sedation, propofolbased sedation presents similar rates of adverse events, provides better sedation, greater patient cooperation, and higher post-procedural patient satisfaction for most endoscopic procedures; it also decreases time to sedation, decreases recovery and discharge times, and provides higher post-anesthesia recovery scores. For advanced endoscopy procedures, compared with sedation by an anesthesiology provider, NAAP presents similar safety but patient and endoscopist satisfaction are lower (high quality evidence).

Propofol sedation does not seem to be associated with an increase in colonic perforation (low to moderate quality evidence).

\section{Background}

Higher post-procedure patient satisfaction is achieved with propofol versus traditional sedation for colonoscopy [10], endoscopic ultrasonography (EUS) [11], endoscopic retrograde cholangiopancreatography (ERCP) [12,13], but not for esophagogastroduodenoscopy (EGD) [10]. Examination quality may also be higher with propofol versus traditional sedation, at least for EGD and ERCP $[12,14]$. Time to sedation and recovery time are shorter with propofol versus traditional sedation $[10,15]$. 
Table 1 Meta-analyses of randomized controlled trials that reported the safety of propofol* versus traditional agents $\dagger$ for sedation during endoscopy.

\begin{tabular}{|c|c|c|c|c|c|c|c|c|}
\hline \multirow[t]{2}{*}{$\begin{array}{l}\text { First author, } \\
\text { year }\end{array}$} & \multirow[t]{2}{*}{ n } & \multirow[t]{2}{*}{ Procedure } & \multicolumn{2}{|c|}{ Hypoxemia, \% (95\%Cl) } & \multicolumn{2}{|c|}{ Hypotension, \% (95\%Cl) } & \multicolumn{2}{|c|}{$\begin{array}{l}\text { Odds ratio for complications, \% } \\
\text { ( } 95 \% \mathrm{Cl})\end{array}$} \\
\hline & & & Propofol & $\begin{array}{l}\text { Traditional } \\
\text { agents }\end{array}$ & Propofol & $\begin{array}{l}\text { Traditional } \\
\text { agents }\end{array}$ & Hypoxemia & Hypotension \\
\hline $\begin{array}{l}\text { Qadeer, } \\
2005[17]\end{array}$ & 1161 & $\begin{array}{l}\text { EGD, colonoscopy, } \\
\text { ERCP, EUS }\end{array}$ & $8.8(\mathrm{NA})$ & 9.9 (NA) & $2.8(N A)$ & 3.0 (NA) & $0.76(0.43-1.35)$ & $1.06(0.53-2.09)$ \\
\hline $\begin{array}{l}\text { McQuaid, } \\
2008 \text { [10] }\end{array}$ & 3918 & EGD, colonoscopy & $11(7-16)$ & $\begin{array}{l}18(12-26) ; \\
6(4-7)^{\ddagger}\end{array}$ & $5(2-10)$ & $7(5-10)$ & $1.11(0.71-1.74)$ & $1.28(0.51-3.26)$ \\
\hline $\begin{array}{l}\text { Singh, } 2008 \\
{[15]}\end{array}$ & $1181^{\S}$ & Colonoscopy & 5.4 (NA) & 6.9 (NA) & 12.5 (NA) & $13.5(\mathrm{NA})$ & $0.73(0.44-1.22)$ & $0.84(0.42-1.69)$ \\
\hline $\begin{array}{l}\text { Wang, } 2013 \\
{[18]}\end{array}$ & 1798 & $\begin{array}{l}\text { EGD, colonoscopy, } \\
\text { ERCP, EUS }\end{array}$ & NA & NA & NA & NA & $0.79(0.58-1.09)$ & $1.46(0.92-2.31)$ \\
\hline
\end{tabular}

$\mathrm{Cl}$, confidence interval; EGD, esophagogastroduodenoscopy; ERCP, endoscopic retrograde cholangiopancreatography; EUS, endoscopic ultrasound; NA, not available.

* Propofol was used as a single agent or combined with other drugs

$\uparrow$ Traditional agents consisted of a benzodiazepine plus an opioid in most trials

Proportions stated separately for midazolam alone (18\%) or midazolam given with a narcotic (6\%)

§ The outcome "hypotension" was analyzed in 321 patients

With regard to adverse events, propofol may cause hypoventilation, hypotension, and bradycardia relatively frequently, but severe adverse events are extremely rare [16]. Therefore, the parameters "hypoxemia" and "hypotension" are most often used as surrogate markers of clinical complications; these were used for comparing propofol with traditional sedation in RCTs that were reviewed in three meta-analyses ( $\bullet$ Table 1$)[10,15,17]$. No significant differences between propofol-based and traditional sedation were detected for hypoxemia or hypotension in these meta-analyses, with the exception that there were fewer cardiopulmonary complications with propofol sedation during colonoscopy versus traditional sedation [17].

\section{New information since 2010}

For unselected procedures and patients, three studies were found:

- A meta-analysis of 22 RCTs that compared propofol monotherapy versus traditional sedation (1798 patients) for GI endoscopy has been added to $\bullet$ Table 1 ; it found shorter recovery and discharge periods, higher post-anesthesia recovery scores, better sedation, and greater patient cooperation with propofol monotherapy compared with traditional sedation, with no increase in cardiopulmonary complications [18]. The healthcare category of the provider of propofol sedation was not mentioned.

- Two prospective, multicenter, non-comparative, surveys from Germany that globally involved $>200000$ patients found a low incidence of propofol-related complications: one survey analyzed endoscopist-administered propofol sedation and reported major adverse events (mask ventilation and laryngospasm) in $0.016 \%$ of patients [19]; in the other study, NAAP was used for sedation in $>90 \%$ of cases, it reported clinically relevant sedation-related complications (defined as respiratory insufficiency that required mechanical ventilation and/or caused hospitalization or prolongation of hospital stay) in $0.042 \%$ of patients and sedation-related death in $0.003 \%$ (not $0.00042 \%$ and $0.00003 \%$ as miscalculated by the authors) [20]. For advanced endoscopic procedures, three meta-analyses were found:

- A meta-analysis of 26 prospective observational trials that compared propofol sedation administered by a non-anesthesia provider versus an anesthesia provider in $>5000$ advanced endoscopic procedures (EUS, ERCP, and deep small-intestinal enteroscopy) [21]. NAAP was associated with similar safety but lower patient and endoscopist satisfaction compared with anesthesia provider-administered propofol sedation.

- Two meta-analyses compared propofol versus traditional sedation, either for advanced endoscopic procedures in general (9 RCTs, 969 patients) [22] or for ERCP alone (6 RCTs, 663 patients) [23]. Propofol was administered by a non-anesthesiologist in 7 of the 9 RCTs including advanced procedures and 3 of the 6 RCTs on ERCP. Both studies found that propofol sedation was associated with a shorter recovery time and a similar incidence of cardiopulmonary adverse events; additionally the largest study found that propofol was associated with a better sedation and amnesia level. The duration of ERCP was similar with propofol versus traditional sedation.

Cost-effectiveness of endoscopist-directed versus anesthesiologist-provided propofol administration was analyzed in the setting of colonoscopy for colorectal cancer screening [24]. If it is assumed that a single nurse would administer propofol and assist the endoscopist with ancillary tasks such as polypectomy, NAAP would be associated with savings over a 10 -year period of $\$ 3.2$ billion in the USA and $€ 0.8$ billion in France [25]. Anesthesiologist involvement adds $20 \%$ and $285 \%$ to the cost of a colonoscopy in the USA and in France, respectively [24,26].

Quality indicators were analyzed in six studies:

- For ERCP, compared with historical controls who had received traditional sedation administered by the endoscopist, patients who received propofol sedation administered by an anesthesiologist had similar rates of deep duct cannulation [27].

- For colonoscopy, five studies were found:

- In a prospective multicenter study, the adenoma detection rate was not independently associated with the drug used for sedation (midazolam versus propofol) [28]. In another multicenter study, compared with no sedation, sedation (using any drug) was associated with a higher cecal intubation rate but no difference in the adenoma detection rate [29]

- With respect to colonoscopy-related perforations, three retrospective studies that included 2536, 6371, and 1144900 colonoscopies found no association between pro- 
pofol sedation and perforation [30-32]. A retrospective study that included 118004 colonoscopies found an overall increase in the perforation risk with propofol [33].

\section{Training in NAAP}

$\nabla$

Statement 2010: Specific knowledge and skills are necessary for endoscopists and nursing staff using NAAP to ensure patient comfort and safety; none of the NAAP reports published to date used self-training to achieve competency in this technique. NAAP performed by endoscopists and endoscopy nurses should not take place without appropriate training, and self-training in NAAP is strongly discouraged. (Evidence level $2++$, Recommendation grade A.) $\mathrm{Gl}$ endoscopists and registered nurses are adequate candidates for NAAP training courses. Previous experience in intensive care medicine is desirable for the physician who is responsible for NAAP. We recommend that training courses for NAAP include a theoretical and a practical part, each part being followed by an examination to document successful training. NAAP training courses should teach techniques of basic life support (BLS) to all participants and advanced cardiovascular life support (ACLS) to caregivers who will practice in locations where an ACLS provider is not immediately available. (Evidence level 4, Recommendation grade D.)

The first human cases of NAAP performed by a caregiver require particular attention because complications are more frequent during this period. We recommend that the first human cases of NAAP performed by an individual be supervised by an anesthesiologist or another person with previous experience of $>300$ NAAP cases (Evidence level 2-, Recommendation grade D). There was dissension in the audience, with some participants recommending preceptorship during the first cases of NAAP without defining "first cases," and others preferring to state a number of cases (evidence only available for $n$ $=30$ ).

Statement 2015: $\mathrm{Gl}$ endoscopists and registered nurses are adequate candidates for NAAP training courses. Previous experience in intensive care medicine or in anesthesia is desirable for the physician who is responsible for NAAP (strong recommendation, low quality evidence). The European curriculum for sedation training in $\mathrm{Gl}$ endoscopy details all aspects of training for non-anesthesiologists who desire to provide NAAP.

\section{Background}

Training is key to safety in endoscopic sedation. In a retrospective study, sedation-related complication rates were significantly lower with advanced experience-level nurses ( $\geq 100$ NAAP procedures) compared with the least-experienced nurses ( $\leq 30$ NAAP procedures) [34].

\section{New information since 2010}

Several curricula for sedation training in GI endoscopy have been issued, in Europe and in the USA [35-37]. The European curriculum is not restricted to NAAP [36]; it discusses all aspects relevant to training in sedation using drugs commonly used for endoscopic sedation and pain control. These aspects include a detailed list of teachers' qualifications, topics to be learned, recommended teaching material, and clinical training, and the evaluation and certification process. The curriculum targets non-anesthesiologist physicians practicing GI endoscopy plus nurses and other allied professionals who are, in accordance with their national laws, involved in sedation for GI endoscopy. For training in NAAP, the curriculum recommends that the trainer responsible for bedside training and for competence assessment should be a physician with previous experience of $>300$ cases of propofol sedation.

A study described the implementation phase of NAAP in an endoscopy unit [38]. A structured training program similar to the European curriculum described above was provided to nurses and endoscopists who would administer propofol, and data were collected prospectively in 1764 patients during a 2.5-year period. Anesthesiologist assistance was requested 10 times ( $0.5 \%$ of the procedures); 8 of these requests occurred among the first quartile of patients sedated by non-anesthesiologists and all were prompted by hypoxemia. As the experience of the NAAP provider increased, the incidence of hypotension decreased (from $73.2 \%$ in the first quartile of patients to $13.3 \%$ in the last quartile; $P<0.000001$ ), whereas the incidence of hypoxemia did not change significantly $(6.1 \%$ and $3.6 \%$ in the first and last quartiles, respectively; $P=0.25)$. In another publication, the same group of authors extended their observation to $>2500$ patients and reported a low complication rate of NAAP (short-lasting hypoxemia, $4.7 \%$; change in blood pressure $>30 \%, 1.3 \%$ ) and no mortality [39].

A nationwide German survey has shown that participants in training courses for endoscopic sedation noted significant improvements in several aspects of their practice relevant to patient safety after training courses [40].

A nationwide Swiss survey has shown that $42 \%$ of 173 gastroenterologists who administered propofol had been actively assisted by an anesthesiologist during the introduction of the sedative agent [3].

\section{Practice of NAAP}

$\nabla$

\subsection{Pre-procedure patient selection}

Statement 2010: Higher categories of the American Society of Anesthesiologists (ASA) physical status classification system and some endoscopic procedures are associated with a higher incidence of complications after endoscopy. Higher Mallampati's classes are associated with more difficult airway management. We recommend that these risk factors are assessed before each NAAP procedure by reviewing patient past medical history, performing a focused physical examination, and assessing type and anticipated complexity of the endoscopic procedure. (Evidence level $2+$, Recommendation grade C.) In the presence of patient-related risk factors for complications, the primary involvement of an anesthesiologist during endoscopy is suggested. These factors include ASA category $\geq 3$, a Mallampati's class of 3 or other conditions at risk for airway obstruction (e. g. pharyngolaryngeal tumors), patients who chronically receive significant amounts of pain medications or in cases of anticipated long-lasting procedure. (Evidence level 4, Recommendation grade D.)

Statement 2015: We recommend that the type of endoscopic procedure and the patient's American Society of Anesthesiologists (ASA) physical status, age, body mass index, Mallampati's classification, and risk factors for obstructive sleep apnea (OSA) be ascertained before each NAAP procedure (strong recommendation, moderate quality evidence). We suggest primary involvement of an anesthesiologist in patients of ASA class $\geq 3$, with a Mallampati's class $\geq 3$ or other conditions that put them at risk of airway obstruction (e.g. pharyngolaryngeal tumors), in patients who chronically receive significant amounts of narcotic analgesics or in cases where a long-lasting procedure is anticipated (weak recommendation, low quality evidence).

\section{Background}

Adequate patient selection for NAAP is critical; well-accepted risk factors for the development of cardiopulmonary complications and mortality include impaired physical status, procedure type, and older age [41-43]. Other clinical features useful to assess before NAAP, using a combination of standardized questionnaires and nurse-based or physician-based assessment, include abnormal head and neck features, chronic obstructive pulmonary disease of stage 3-4, cardiac failure of stage $3-4$, history of bronchoaspiration, trouble with previous anesthesia or sedation, allergies, current medications, tobacco, alcohol, and drug consumption [44]. After undergoing a physical examination that in- 
Table 2 Propofol sedation-related adverse events in patients with versus without obstructive sleep apnea (OSA).

\begin{tabular}{|c|c|c|c|c|c|c|c|c|c|}
\hline \multirow{2}{*}{$\begin{array}{l}\text { First author, } \\
\text { year }\end{array}$} & \multirow[t]{2}{*}{ Study design } & \multirow[t]{2}{*}{$\mathbf{n}$} & \multirow[t]{2}{*}{ Procedure } & \multirow[t]{2}{*}{ Sedation provider } & \multirow{2}{*}{$\begin{array}{l}\text { Diagnostic } \\
\text { criteria for OSA }\end{array}$} & \multicolumn{2}{|c|}{ Hypoxemia } & \multicolumn{2}{|c|}{ Hypotension } \\
\hline & & & & & & OSA- & OSA+ & OSA- & OSA+ \\
\hline $\begin{array}{l}\text { Mehta, } 2014 \\
\text { [52] }\end{array}$ & Prospective & 243 & $\begin{array}{l}\text { EGD/ colonos- } \\
\text { copy }\end{array}$ & $\begin{array}{l}\text { Anesthesiologist or } \\
\text { certified registered } \\
\text { nurse anesthetist }\end{array}$ & STOP-BANG $\geq 3$ & $14 / 125$ & $20 / 118$ & $13 / 125$ & $7 / 118$ \\
\hline $\begin{array}{l}\text { Deng, } 2012 \\
\text { [60] }\end{array}$ & Prospective & 210 & Colonoscopy & Anesthesiologist & STOP $\geq 2$ & $3 / 178$ & $10 / 32$ & NA & NA \\
\hline $\begin{array}{l}\text { Adler, } 2011 \\
\text { [138] }\end{array}$ & Retrospective & 112 & $\begin{array}{l}\text { EGD/ colonos- } \\
\text { copy }\end{array}$ & NAAP & Confirmed* & $1 / 55$ & $4 / 57$ & $2 / 55$ & $8 / 57$ \\
\hline $\begin{array}{l}\text { Corso, } 2012 \\
{[139]}\end{array}$ & Prospective & 272 & $\begin{array}{l}\text { EGD/ colonos- } \\
\text { copy/ ERCP }\end{array}$ & NA & STOP-BANG $\geq 3$ & $2 / 131$ & $21 / 141$ & NA & NA \\
\hline $\begin{array}{l}\text { Friedrich- } \\
\text { Rust, } 2014 \\
{[51]}\end{array}$ & $\begin{array}{l}\text { Randomized } \\
\text { controlled trial }\end{array}$ & 533 & $\begin{array}{l}\text { EGD/ colonos- } \\
\text { copy }\end{array}$ & $\begin{array}{l}\text { NAAP or anesthe- } \\
\text { siologist }\end{array}$ & Clinical history & $120 / 513$ & $13 / 20$ & NA & NA \\
\hline $\begin{array}{l}\text { Coté, } 2010 \\
{[140]}\end{array}$ & Prospective & 231 & ERCP/EUS & Anesthesiologist & STOP-BANG $\geq 3$ & $4 / 131$ & $12 / 100$ & $22 / 131$ & $14 / 100$ \\
\hline \multicolumn{6}{|c|}{ Subtotal (EGD/ colonoscopy) } & $18 / 358$ & $34 / 207^{\dagger}$ & $15 / 180$ & $\begin{array}{l}15 / 175 \\
\text { (n.s.) }\end{array}$ \\
\hline \multicolumn{6}{|c|}{ Total (all procedures) } & $24 / 620$ & $67 / 448^{\dagger}$ & $37 / 311$ & $\begin{array}{l}29 / 275 \\
\text { (n.s.) }\end{array}$ \\
\hline
\end{tabular}

EGD, esophagogastroduodenoscopy; ERCP, endoscopic retrograde cholangiopancreatography; EUS, endoscopic ultrasonography; NAAP, non-anesthesiologist administration of propofol; NA, not available; n.s., not significant; STOP, STOP score (loud Snoring,

Tiredness, Observed apnea, high blood Pressure); STOP-BANG, STOP-BANG score (loud Snoring, Tiredness, Observed apnea, high blood Pressure-Body mass index, Age, Neck circumference, and Gender).

* Using polysomnography, portable monitoring, or on clinical grounds given their history and positive response to the use of a continuous positive airway pressure (CPAP) machine ${ }^{\dagger} P<0.001$

cludes vital signs, heart and lung auscultation, as well as throat examination, the patient is classified according to the ASA physical status scale and Mallampati's class $[45,46]$.

The presence of some patient-related risk factors may trigger consideration of primary involvement of an anesthesiologist during endoscopy [47]. Such factors are, for example: a history of stridor, snoring, or OSA; patients with dysmorphic facial features or oral abnormalities, such as a small opening ( $<3 \mathrm{~cm}$ in an adult), high arched palate, or macroglossia; patients with neck or cervical spine abnormalities, tracheal deviation, or advanced rheumatoid arthritis; patients with jaw abnormalities, such as micrognathia; patients receiving significant amounts of narcotic analgesics chronically or who for other reasons may be tolerant to agents used during sedation and analgesia.

\section{New information since 2010}

- Increasing ASA class was confirmed to be associated with a stepwise increase in the odds ratio of serious adverse events in the Clinical Outcomes Research Initiative (CORI) database (1 590648 endoscopic procedures; 1318495 patients). Odds ratios for serious adverse events (hospital admission, surgery, cardiopulmonary resuscitation, or emergency room referral) were, using a reference value of 1 for ASA class 1, for EGD: ASA class 2, 1.54 (95\% confidence interval [CI] 1.31 - 1.82); class 3, 3.90 (95\%CI 3.27 - 4.64); classes 4/5, 12.02 (95\%CI 9.62 $15.01)$; and for colonoscopy were: ASA class 2, 0.92 (95\%CI $0.85-1.01)$; class 3, 1.66 (95\%CI 1.46-1.87); classes 4/5, 4.93 (95\%CI 3.66-66.3) [48]. A similar trend for ERCP was not significant. The sedation type was not detailed in this study. Another prospective registry study (13 747 endoscopic procedures under propofol sedation) showed that all of the 17 severe complications that were observed occurred in patients of ASA class $\geq 3$ [49].
- Increasing age was also associated with a stepwise increase in the incidence of serious adverse events in the above-mentioned CORI study [48]. In a prospective study of EGD/colonoscopy performed in 10000 patients, with NAAP used in $96 \%$ of the cases, sedation-related cardiorespiratory adverse events were associated with older age [50]. In two other prospective studies (one RCT) totaling 773 patients, age was an independent predictor of sedation-related adverse events during colonoscopy under propofol sedation [51, 52]. Nevertheless, various studies have suggested that NAAP may be safely performed in elderly patients for various endoscopic procedures including ERCP [53 -55]. The doses of propofol administered should be adapted in the elderly: in patients older than 90 years, a dose less than half of that administered to controls provided similar sedation levels and propofol blood concentrations [56].

- Body mass index (BMI) was independently associated with sedation-related complications in two series of 799 and 1016 patients undergoing advanced endoscopic procedures under propofol, as were ASA class $\geq 3$ (two studies), age and male sex (one study each) $[57,58]$. Patients were not screened for OSA in these studies (OSA is associated with high BMI [59]). In addition, for colonoscopy under propofol sedation, higher BMI was associated with sedation-related adverse events in two prospective studies (773 patients, 1 RCT) [51, 52].

- OSA is an underdiagnosed entity; in some settings, $15 \%-48 \%$ of the patients undergoing routine endoscopic procedures are at risk of OSA [52, 60, 61]. Patients at high risk of OSA, as identified by questionnaires, as well as those with confirmed OSA present a higher risk of hypoxemia during propofol sedation for endoscopy compared with non-OSA controls ( $\bullet$ Table 2 ). Various questionnaires are available to screen patients for OSA [62]; the STOP-BANG questionnaire (loud Snoring, Tiredness, Observed apnea, high blood Pressure-Body mass index, Age, 
Neck circumference, and Gender) is a list of eight questions that is easy to fill and interpret and that has been validated in both unselected and obese patients $[63,64]$. It provides a high negative predictive value for the diagnosis of moderate (90\%) and severe (100\%) OSA [63], and it is the most frequently used tool to screen for OSA before endoscopy. In an RCT that included 533 patients [51], OSA was an independent predictor of hypoxemia during colonoscopy under propofol sedation, together with older age, BMI, and total dose of propofol.

- In cirrhotic patients, a meta-analysis of five RCTs that compared propofol versus midazolam for upper GI endoscopy found similar safety for both regimens; propofol sedation was associated with a shorter deterioration of psychometric scores than midazolam [65]. However, most studies included patients with Child A and B cirrhosis only. Propofol was administered by a non-anesthesiologist in three of the five RCTs.

Risk classification of patients before NAAP may be performed using a combination of review of a patient's past medical history, questionnaires (e.g. the STOP-BANG questionnaire), and a focused physical examination.

Patients of ASA classes 3 and 4 are included in NAAP studies with increasing frequency, even for advanced endoscopic procedures, as shown in the latest meta-analysis of NAAP (ASA class 3-4 patients accounted for $29 \%$ of the patients included in the studies that detailed ASA category; 257 of 896 patients) [21]. No impact on patient safety has been detected. Sedation-related deaths are however most frequently reported in these categories of patients [20].

\subsection{Performance of sedation \\ 5.2.1 Personnel}

Statement 2010: In the vast majority of NAAP studies, propofol was administered by a person who had patient sedation as his/her sole task (Evidence level $1++)$. It is recommended that patients be continuously monitored by a person dedicated to NAAP. (Recommendation grade A).

Statement 2015: No new recommendation could be made about the necessity of continuous patient monitoring by a person dedicated to NAAP.

\section{Background}

Various guidelines have recommended that NAAP be performed by a person who has NAAP as his/her sole task based on the fact that early studies demonstrating the safety of NAAP were performed under these conditions [66-68]. Several reports had suggested that propofol administration in the presence of the endoscopist and a single nurse is safe but these reports did have limitations [69].

\section{New information since 2010}

A study of prospectively collected adverse events that included 13747 endoscopic procedures under NAAP has been reported [49]; it is a retrospective comparison of two 2-year periods, each with similar numbers of endoscopies, one with a person dedicated to NAAP in all of the cases and the other without someone dedicated to NAAP for "most endoscopic procedures." Sedationrelated circulatory complications tended to be less frequent during the period with a person dedicated to NAAP compared with the other period but no significant differences were observed. The study found that all of the 17 severe complications occurred in patients of ASA class $\geq 3$ but, because of its limitations, this study does not allow the conclusion to be drawn that both approaches are equally safe.

Three surveys reporting that NAAP is commonly practiced with no staff member dedicated exclusively to sedation during NAAP were identified:

- In a survey of gastroenterologists practicing in Switzerland, $67 \%$ of the 158 survey respondents who were regularly using NAAP stated that a single assistant was present during EGD and colonoscopy [3]. The overall complication rate was comparable with that reported in other large studies (morbidity and mortality rates of $0.14 \%$ and $0.0018 \%$, respectively). Of the gastroenterologists performing NAAP, $61 \%$ had either undergone formal training in anesthesiology or a 6-month training period in an intensive care unit during their training in internal medicine.

- In a prospective multicenter survey from Germany that involved 191142 patients, NAAP was used in approximately 90\% of patients and no additional person was present for NAAP "in a majority of cases" (no more information was available) [20]. Complications were defined as respiratory insufficiency that required mechanical ventilation and/or caused hospitalization or prolongation of hospital stay. Overall, the endoscopy-related complication rate was $0.22 \%(n=424)$ and the sedationrelated complication rate was $0.042 \%(n=82)$. A limitation of this study is that hypoxemic events requiring bag and mask ventilation were not registered. Sedation-related death occurred in six patients ( $0.003 \%)$, all of them classified as ASA 3 before endoscopy, and occurred in the presence of an additional person trained for NAAP.

- Finally, an international survey showed that NAAP was used by $30 \%$ of 48 gastroenterologists and that one-third of them did not have a person dedicated solely to propofol administration [4].

An online survey performed after extended discussion and provision of the relevant literature to all of the authors of this Guideline found that half of all authors supported a modification of the staff requirements for NAAP in well-defined conditions while the other half wanted to keep the 2010 recommendation unchanged. The ESGE/ESGENA NAAP task force emphasizes that patient safety was the highest priority when elaborating this Guideline.

Statement 2010: There is no evidence that quick availability of a life support team is required for propofol administration. We do not recommend compulsory availability of a life support team if propofol is administered in the presence of a person trained in ACLS. (Evidence level 2+; Recommendation grade C.)

Statement 2015: No changes (weak recommendation, very low quality evidence).

\section{Background}

No study has analyzed if availability of a life support team modifies any aspect of NAAP.

\section{New information since 2010}

None.

\subsubsection{Patient preparation and monitoring}

Statement 2010: Intravenous access is required for sedation in GI endoscopy and should be maintained using a catheter, not a winged steel needle, until full patient recovery. (Evidence level 4, Recommendation grade D.) 
Statement 2015: No changes (weak recommendation, moderate quality evidence).

\section{Background}

Reliable intravenous access is required for the duration of NAAP; Teflon cannulas are as easy to insert as winged steel needles and provide more reliable intravenous access [70].

\section{New information since 2010}

None.

Statement 2010: Continuous supplemental oxygen is indicated during NAAP for endoscopy. (Evidence level 1+, Recommendation grade B.)

Statement 2015: No changes (strong recommendation, moderate quality evidence).

\section{Background}

Administration of oxygen is widely recommended because RCTs have shown that oxygen desaturation is frequent during endoscopy if the patient breathes room air and that this may be prevented by supplemental oxygen administration during endoscopy under traditional sedation [71-78]. However, the potential benefit of routine prophylactic oxygen supplementation in terms of decreased cardiopulmonary complications is unclear [79].

\section{New information since 2010}

Regular use of supplemental oxygen during sedated endoscopy, using propofol or other drugs, was reported by $39 \%, 35 \%-42 \%$, $20 \%-41 \%$, and $58 \%-78 \%$ of respondents to nationwide surveys in Italy, Germany, Greece, and Switzerland, respectively [3].

Statement 2010: Patient monitoring is recommended in all patients using continuous pulse oximetry and automated noninvasive blood pressure measurement (at baseline and then at 3-5-minute intervals) during both NAAP and the recovery period; continuous electrocardiography is recommended in selected patients with a history of cardiac and/or pulmonary disease. Baseline, minimum and maximum heart rate/blood pressure, as well as baseline and minimum oxygen blood saturation should be recorded. (Evidence level 2++ Recommendation grade $\mathrm{B}$.)

Statement 2015: No changes (strong recommendation, moderate quality evidence).

\section{Background}

Most studies that have established the safety of NAAP have used patient monitoring as stated above [16]. Although their clinical utility has not been demonstrated, the equipment is widely available, inexpensive, and easy to use. Hypoxemia, but not hypoventilation, can be detected early with pulse oximetry. As hypotension is a frequent side effect of propofol that requires intervention, blood pressure monitoring seems to be useful. Monitoring of these parameters has become standard practice for NAAP $[80,81]$.

\section{New information since 2010}

Pulse oximetry monitoring during sedated endoscopy, using propofol or other drugs, was reported by $\geq 90 \%$ of respondents to nationwide surveys in Italy, Germany, Greece, and Switzerland [3]. The Swiss survey detailed figures for NAAP: pulse oximetry and blood pressure monitoring were used by $100 \%$ and $66 \%$ of respondents, respectively [3].
Statement 2010: Visual assessment of respiratory activity during anticipated long endoscopy procedures is not a reliable method of detecting apnea. During NAAP, capnographic monitoring of respiratory activity may reduce episodes of hypoxemia during long endoscopic procedures or when visual assessment of patient breathing is impaired, but no clinical impact has been demonstrated. Therefore, capnography cannot be recommended as standard. (Evidence level 1+, Recommendation grade B.)

Statement 2015: We suggest consideration of capnographic monitoring during NAAP in specific situations including high risk patients, intended deep sedation, and long procedures (weak recommendation, high quality evidence).

\section{Background}

Detection of hypoventilation and apnea using visual inspection of respiratory activity is unreliable [82]. The lag times from start of apnea to capnographic findings and to hypoxemia are about 5 seconds and another 10-20 seconds [83], so that capnography provides an "early warning" window for interventions aimed at improving ventilation. Two RCTs reported that hypoxemia was more frequently and more reliably detected if capnography was available $[84,85]$ but no difference in clinical outcome was found whether or not capnography was used. Both RCTs used traditional sedation, for either advanced endoscopy procedures in adults [84], or EGD/colonoscopy in children [85]. False-positive results (flat capnography line) were observed in one of these studies in a significant proportion of patients [84].

\section{New information since 2010}

In its 2011 revision of the "Standards for basic anesthetic monitoring," the ASA states "During moderate [italics added] or deep sedation the adequacy of ventilation shall be evaluated by continual observation of qualitative clinical signs and monitoring for the presence of exhaled carbon dioxide unless precluded or invalidated by the nature of the patient, procedure or equipment" [86]. The American Society for Gastrointestinal Endoscopy, the American Gastroenterological Association, and the American College of Gastroenterology answered that "There are insufficient data to demonstrate that improved clinical outcomes or care quality derive from the use of capnography in adults undergoing targeted moderate sedation for upper endoscopy and colonoscopy" [87]. Reluctance toward generalized use of carbon dioxide monitoring was also motivated by costs.

Three recent RCTs have compared standard monitoring with versus without capnography during GI endoscopy procedures under propofol sedation in a total of 1833 patients $[51,88,89]$. Sedation was provided by non-anesthesiologists in two RCTs [88, 89], and by anesthesiologists or non-anesthesiologists in one [51]. The RCTs included patients who underwent colonoscopy (2 studies) or unselected endoscopy procedures (1 study). All RCTs found a lower incidence of oxygen desaturation with capnography versus without, and the difference reached statistical significance in two RCTs $[51,88]$. The drawbacks of capnography include cost and false alarms that may lead to unnecessary procedure interruption, delay, or termination.

Statement 2010: Electroencephalogram (EEG)-based monitoring may be used during NAAP to target a sedation level; it may help to reduce propofol consumption during complex endoscopic procedures with targeted deep sedation. No clinical impact of EEG-based monitoring has been demonstrated (Evidence level 1+), and no specific recommendation is made due to the paucity of data. 
Statement 2015: We do not recommend using the bispectral index (BIS) during NAAP (strong recommendation, high quality evidence).

\section{Background}

The BIS is an EEG-derived parameter that has been used during NAAP to achieve a target sedation level. The use of the BIS compared with clinical parameters during propofol sedation for endoscopy had been assessed by four RCTs [90-93]. Two of these found no difference in propofol consumption or recovery time for colonoscopy and gastric endoscopic submucosal dissection [92, 93]; the other two found lower propofol doses were used and recovery times were shorter for ERCP in the BIS-monitored group $[90,91]$. No side effect had been attributed to the use of BIS.

\section{New information since 2010}

An RCT that included 144 patients undergoing ERCP showed no difference in cardiopulmonary complications, numbers of hypoxemic events, mean propofol doses, and quality of sedation whether or not BIS monitoring was used [94]. Recovery times after the procedure were shorter with BIS but the clinical benefit for daily practice was limited (mean duration from end of endoscopy until leaving the procedure room was 5.9 minutes versus 7.5 minutes, with versus without BIS, respectively). Three RCTs that included patients undergoing ERCP $(n=59)$ [95], colonoscopy ( $n$ $=115)$ [96], and gastric ESD $(n=180)$ [97] found no clinically significant advantage associated with the use of BIS monitoring.

\subsubsection{Level of sedation}

Statement 2010: Simple endoscopic procedures can be performed with moderate sedation, maintaining a high degree of patient satisfaction. Prolonged or complex procedures (e. g. EUS and ERCP) are frequently performed under deep sedation. (Evidence level 1++, Recommendation grade A.)

Statement 2015: No changes (strong recommendation, high quality evidence).

\section{Background}

The level of sedation can be assessed using different scales; an example is given in Table $3[47,98,99]$. The targeted levels of sedation are usually moderate for EGD/ colonoscopy and deep for advanced procedures, such as EUS-guided fine needle aspiration (EUS-FNA) and ERCP.

\section{New information since 2010}

In a retrospective study of $486 \mathrm{ERCP}$ procedures performed under targeted moderate sedation using midazolam and an opioid, the procedure could not be completed in $14 \%$ of the cases because of patient intolerance [100]. Independent predictors of failed ERCP under moderate sedation included substance abuse and higher difficulty of intervention as assessed on a standardized 3-point scale [101].

\subsubsection{Protocols of propofol-based sedation}

\subsubsection{Propofol alone or combined with other drugs}

Statement 2010: Combining propofol with an additional drug (benzodiazepine/opioid/ketamine) allows the dose of propofol administered to be decreased without reproducible effect on recovery time; there is no clear evidence that combining propofol with another drug leads to a decrease in adverse effects (Evidence level 1+). No recommendation is made about combination of propofol with other drugs.

Statement 2015: We suggest propofol monotherapy except in particular situations (weak recommendation, high quality evidence).

\section{Background}

Seven RCTs had compared sedation with propofol administered alone or combined with various drugs. No consistent difference had been found between the two regimens, except that a lower dose of propofol was administered if it was combined with traditional sedative agents.

\section{New information since 2010}

A meta-analysis of 9 RCTs (1505 patients) that compared propofol monotherapy versus propofol combined with traditional sedative agents found no significant differences between the groups in terms of complications (hypoxemia, hypotension, arrhythmias, and apnea) and of amnesia; the total dose of propofol was lower if propofol was combined with traditional sedative agents [102].

Propofol monotherapy presents the advantage of allowing more rapid patient recovery as the half-life of propofol is shorter than that of all other drugs used for sedation $[103,104]$. However, in some individual situations, low dose midazolam premedication might be beneficial to facilitate intravenous line placement and to reduce the need for propofol [105]. Such situations include patients with a high anxiety potential, long-lasting procedures in patients with a known important need for sedatives, and patients with limited left ventricular function or with previous pronounced hypotension following propofol administration [106].

\subsubsection{Propofol administration techniques}

Statement 2010: Intermittent bolus administration of propofol is the current standard administration technique for NAAP. Data about propofol administration using perfusor systems during endoscopy are accumulating and show that these systems are as effective and safe as the standard technique. Patient-controlled sedation (PCS) is a valid administration technique but it is not applicable in a significant minority of patients. (Evidence level $1+$.)

Table 3 Stages of sedation modified according to the American Society of Anesthesiologists [47].

\begin{tabular}{|c|c|c|c|c|}
\hline & Minimal (anxiolysis) & Moderate & Deep & Anesthesia \\
\hline Reaction being addressed & $\begin{array}{l}\text { Patient reaction is adequate } \\
\text { to verbal commands }\end{array}$ & $\begin{array}{l}\text { Somnolence, reaction to } \\
\text { louder commands, if needed } \\
\text { with additional tactile stim- } \\
\text { ulation }\end{array}$ & $\begin{array}{l}\text { Somnolence, hard to wake, } \\
\text { targeted reaction to repeat- } \\
\text { ed tactile stimulation and } \\
\text { pain stimulus }\end{array}$ & $\begin{array}{l}\text { Patient cannot be woken, } \\
\text { not even in response to pain } \\
\text { stimuli }\end{array}$ \\
\hline Spontaneous breathing & Not influenced & Adequate & $\begin{array}{l}\text { Respiratory function mildly } \\
\text { restricted }\end{array}$ & $\begin{array}{l}\text { Inadequate, orotracheal } \\
\text { intubation or larynx mask } \\
\text { necessary }\end{array}$ \\
\hline
\end{tabular}


Statement 2015: We recommend administering propofol through intermittent bolus infusion or perfusor systems, including target-controlled infusion (TCI), and considering patient-controlled sedation (PCS) in particular situations (strong recommendation, high quality evidence).

\section{Background}

Most trials dealing with propofol for GI endoscopy have used repeat bolus injections by a caregiver or continuous infusion at a fixed rate; other techniques include PCS, TCI of propofol and "computer-assisted personalized sedation" (CAPS).

In PCS, a pump is programmed to deliver intravenously a predetermined amount of sedative and/or opioid when the patient presses a button. When given the choice between PCS and propofol administration by a trained nurse, about one third of patients refuse PCS although safety seems similar with both methods $[107,108]$. PCS is advantageous in terms of cost as no dedicated nurse is required.

In TCI or CAPS, the infusion rate is adjusted by a computer, either (for TCI) in an "open-loop" system based on fixed parameters such as body weight or (for CAPS) in a "closed-loop" system that uses feedback from a real-time measure of drug effect such as patient reaction to tactile stimuli or BIS monitoring.

\section{New information since 2010}

A CAPS system (Sedasys [SED]; Ethicon Endo-Surgery, Inc., Blue Ash, Cincinnati, Ohio, USA) was approved by the Food and Drug Administration in 2013. This system is designed to facilitate propofol-based mild to moderate sedation mainly during diagnostic endoscopies in patients of ASA classes 1-2. A multicenter RCT compared SED with traditional sedation for EGD $(n=279)$ and colonoscopy $(n=721)$ [109]. Adverse events presented with a similar incidence in the traditional sedation and SED groups but, compared with traditional sedation, SED provided greater clinician and patient satisfaction as well as faster patient recovery. Several criticisms have been made of this RCT [110].

A single RCT compared TCI versus PCS for propofol administration [111]. The examination consisted of ERCP and only $7 \%$ of invited patients declined to participate. Compared with anesthesiologist-administered TCI, PCS was characterized by a lower dose of propofol, lower sedation levels, similar patient satisfaction, and shorter discharge time. This confirmed findings from another RCT by the same authors where PCS was compared with anesthesiologist-administered propofol without TCI [112]. The authors recommended considering PCS as a feasible option for propofol administration during ERCP.

TCI propofol administration was compared with traditional sedation for EGD and colonoscopy in an RCT [113]. TCI-administered propofol was associated with shorter recovery time and higher patient/endoscopist satisfaction.

In patients with mild to moderate chronic obstructive pulmonary disease, a stepwise sedation regimen with incremental doses of propofol/midazolam was found to be superior to continuous propofol/midazolam administration during EGD in terms of effectiveness and safety in an RCT [114].

\subsubsection{Non-pharmacological measures available to reduce doses of propofol}

\subsubsection{Listening to music}

Statement 2010: Listening to patient-selected music during colonoscopy allows the dose of propofol administered to be decreased; we recommend this for colonoscopy. (Evidence level 1 -, Recommendation grade B.)

Statement 2015: We suggest that patients listen to self-selected music during upper and lower $\mathrm{Gl}$ endoscopy procedures (weak recommendation, moderate quality evidence).

\section{Background}

Music has historically been used as a non-pharmacological method used for relieving patient anxiety and pain.

\section{New information since 2010}

A new meta-analysis reviewed 21 RCTs that compared patients undergoing various endoscopic examinations with versus without music (total number of patients, 2134) [115]. Of these RCTs, 15 included upper and lower GI endoscopy procedures, while six RCTs included genitourinary or pulmonary endoscopy procedures. Listening to music during endoscopy was associated with significant improvements in pain and in anxiety, a lower heart rate and arterial blood pressure, as well as higher satisfaction scores. Better results were observed for GI as compared with non-GI endoscopy procedures; for GI endoscopies, procedure duration was shorter with music, although the doses of sedatoanalgesic drugs were not significantly decreased in the music group compared with the control group. However, most of the trials included in this meta-analysis used traditional sedative regimens rather than propofol.

\subsubsection{Pharyngeal anesthesia}

Statement 2010: The role of pharyngeal anesthesia during propofol sedation for upper digestive endoscopy has not been assessed. No recommendation is made.

Statement 2015: We do not suggest using pharyngeal anesthesia during propofol sedation monotherapy for upper GI endoscopy (weak recommendation, moderate quality evidence).

\section{Background}

Pharyngeal anesthesia decreases patient discomfort during upper GI endoscopy under traditional sedation [116].

\section{New information since 2010}

Two placebo-controlled RCTs examined the effect of pharyngeal lidocaine (40 mg and $50 \mathrm{mg}$ ) on EGD under propofol monotherapy sedation in 419 patients $[117,118]$. Both RCTs found that topical pharyngeal anesthesia did not reduce the necessary dose of propofol or improve the anesthetist's or endoscopist's satisfaction with the procedure; one RCT found that the use of lidocaine topical pharyngeal anesthesia reduced the gag reflex and that this had no clinical consequence. 


\subsubsection{Precautions and management of complications}

Statement 2010: Propofol is contraindicated in patients with a known allergy to soy protein. Pain at the injection site is frequent and can be prevented by lidocaine (Evidence level 1++). Hypoxemia and hypotension are the most frequent adverse effects of propofol and develop during NAAP in $5 \%-10 \%$ of patients. Measures to be taken in case of complications should be established in a check-list that is updated and tested at regular intervals. If a patient proves difficult to sedate adequately for the examination purpose, endoscopy termination and referral to an anesthesiologist should be considered (Evidence level 4, Recommendation grade D).

Statement 2015: No changes.

\section{Background}

Propofol is contraindicated in patients with a known allergy to soy protein. Recommendations about allergies to other components (e.g. eggs, peanuts, sulfites) vary depending on the propofol formulation.

Hypoxemia and hypotension, the most frequent adverse events with propofol, are usually defined as hemoglobin oxygen saturation $<90 \%$ and systolic blood pressure $<90 \mathrm{mmHg}$, respectively. Their incidence during propofol-based sedation was, in a meta-analysis, $11 \%(95 \% \mathrm{CI} 7 \%-16 \%)$ and 5\% (95\%CI 2\%-10\%), respectively [10].

Treatment of hypoxemia includes discontinuing the infusion of sedative drugs, increasing oxygen administration, and maintaining airway patency. Flumazenil/naloxone may be administered if benzodiazepines/opioids have been used. If the patient does not respond adequately to these measures, endoscopy should be stopped. If hypoxemia does not reverse, an emergency call must be made according to local protocols and ACLS must be initiated. Hypotension is treated with administration of intravenous crystalloid solution and, if needed, vasopressor catecholamines. In cases of bradycardia, atropine should be administered intravenously.

Strict aseptic conditions should be maintained during manipulation of propofol $[119,120]$. Propofol may cause pain at the injection site; this may be prevented by intravenous administration of lidocaine $(0.5 \mathrm{mg} / \mathrm{kg})$ with a rubber tourniquet on the forearm [121].

\section{New information since 2010}

In a nonrandomized controlled trial that included 216 patients undergoing EGD and/or colonoscopy under propofol combined with midazolam, routine placement of a Wendl nasopharyngeal tube reduced the frequency of hypoxemic events during endoscopic sedation, with $4.7 \%$ of the patients showing minor nasopharyngeal injury [122].

With respect to allergy to soy oil as a contraindication to propofol administration, evidence has appeared that refined soy oil, such as that present in propofol, could be safe for people with soy allergy because the allergenic proteins are removed during the refining process [123].

\subsection{Post-sedation care}

\subsubsection{Surveillance during recovery}

Statement 2010: A small minority of sedation-related adverse effects occur after, as opposed to during, the procedure. We recommend patient observation until discharge by a person who is aware of the adverse effects of the drugs administered. (Evidence level $2+$, Recommendation grade C.)
Statement 2015: No changes (strong recommendation, low quality evidence).

\section{Background}

Serious adverse events may occur up to 30 minutes after the administration of benzodiazepines and opioids for sedation, but post-procedure adverse events represent a small minority of sedation-related adverse events and are less frequent with propofol compared with a combination of benzodiazepines and opioids $[13,124]$. During recovery, patients should be observed by a person who is aware of the adverse events of the drugs administered, using monitoring equipment similar to that used during the procedure. This person may perform minor interruptible tasks but should not leave the room.

\section{New information since 2010}

None.

\subsubsection{Discharge}

Statement 2010: Minimum discharge criteria are useful for discharging patients after sedation for digestive endoscopy. We recommend using standardized discharge scoring form. (Evidence level $2+$, Recommendation grade C.)

Statement 2015: We suggest using the post-anesthetic discharge scoring system (PADSS) to determine when patient recovery is sufficient to allow discharge (weak recommendation, low quality evidence).

\section{Background}

Following sedated endoscopy, clinical criteria are most commonly used for deciding when to discharge a patient. In contrast, following surgery, the patient transition from Phase I to Phase II recovery (discontinuation of anesthesia until return of protective reflexes and motor function) and then from Phase II to Phase III recovery (patient returning home) is usually assessed using scoring systems such as the modified Aldrete score (Phase I to Phase II) and the PADSS (Phase II to Phase III) [125,126]. Despite some limitations of PADSS inherent to its focus on surgical procedures (e.g. one of the five criteria in this system is "surgical bleeding"), it has been documented, in a relatively small prospective study, to allow safe discharge after GI endoscopy [127].

\section{New information since 2010}

A prospective study compared PADSS versus clinical criteria for the determination of sufficient patient recovery to permit discharge after outpatient colonoscopy under traditional sedation [128]; use of PADSS allowed earlier discharge. During follow-up phone calls, no hospital re-admissions related to endoscopy were identified.

Statement 2010: Minimum discharge criteria should be fulfilled before discharging a patient. However, psychomotor functions remain significantly impaired when standard discharge criteria are met. Upon discharge, patients should be accompanied by a responsible person and refrain from driving, operating heavy machinery, or engaging in legally binding decisions for at least 12 hours if sedation with propofol alone was administered ( 24 hours in cases of combined regimen). Advice should be provided verbally and in written form, including a 24-hour contact phone number. (Evidence level 1+, Recommendation grade $\mathrm{A}$.)

Statement 2015: Minimum discharge criteria should be fulfilled before discharging a patient. We recommend that patients who have received combined regimens, and all patients of ASA class $>2$, should upon discharge be accompanied by a responsible person and refrain for $\mathbf{2 4}$ hours 
from driving, drinking alcohol, operating heavy machinery, or engaging in legally binding decisions. Advice should be provided verbally and in written form to the patient, including a 24-hour contact phone number (strong recommendation, low quality evidence).

For patients of ASA classes 1-2 who have received low dose propofol monotherapy, a 6-hour limit is suggested (weak recommendation, low quality evidence).

\section{Background}

Psychomotor functions remain significantly impaired when standard discharge criteria are met [129]. Therefore, patients should be informed in advance of precautions to be taken after discharge; these instructions should be repeated at the time of discharge. Precautions include the presence of an escort to ensure safe return home following outpatient procedures. Advice should be provided verbally and in written form, including a 24hour contact phone number.

Current recommendations from various professional associations to neither drive nor use public transport without an accompanying person, nor operate heavy machinery or engage in any legal decision-making for 24 hours seem too strict if propofol is used in low dose monotherapy. In a study, $92 \%$ of 400 patients who received low dose propofol for EGD wanted to drive when leaving the endoscopy unit, and all did so without incident [130].

\section{New information since 2010}

In a prospective study of 48 patients of ASA classes 1 - 3 who underwent colonoscopy under propofol monotherapy, psychomotor recovery, driving ability, and blood concentrations of propofol were within normal limits 1 hour after colonoscopy [103]. In another prospective study of 2101 patients of ASA classes $1-2$ who underwent outpatient colonoscopy under low dose propofol monotherapy, $65 \%$ of the patients drove safely to their home or office after their colonoscopy [104]. An RCT that compared three sedation regimens for colonoscopy, namely propofol monotherapy, propofol-fentanyl, and midazolam-fentanyl, in 96 patients showed that propofol monotherapy had the least impact on post-procedure cognitive function [131].

\subsection{Procedure documentation and medicolegal issues}

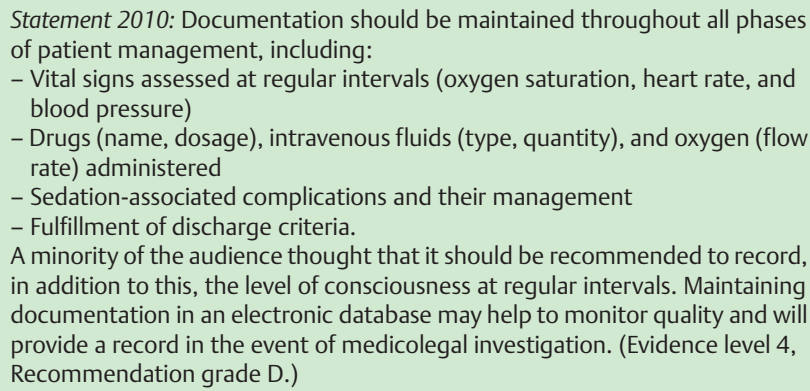

Statement 2015: No changes (weak recommendation, low quality evidence)

\section{Background}

A structured procedural sedation record is part of the quality process and may help to improve compliance with sedation guidelines [132].

\section{New information since 2010}

None.

Statement 2010: The endoscopist bears the ultimate medicolegal responsibility to ensure proper personal training of the endoscopy staff involved in NAAP. (Evidence level 4.)

Statement 2015: No changes (low quality evidence).

\section{Background}

The fact that the label accompanying propofol packages in many countries stipulates that "propofol should be administered only by persons trained in the administration of general anesthesia" means that, in some countries, during NAAP propofol is used "off-label." Off-label use of drugs is common in medical practice and it has been endorsed by various associations, such as the Food and Drug Administration and the American Medical Association [133]. However, departure from label recommendations may in some courts shift to the defendant the burden of proving that the method of use accords with recognized clinical practice.

\section{New information since 2010}

None.

\begin{abstract}
Statement 2010: Informed consent for NAAP should be obtained from the patient or his/her legal representative according to domestic laws and regulations in a way similar to that of other endoscopy procedures. It is generally obtained during a face-to-face discussion between a physician familiar with the procedure and the patient, with information given in lay language to the patient and the opportunity for him/her to ask questions prior to the procedure. The informed consent regarding sedation issues may be incorporated into the main body of the endoscopy consent form. The procedure of informed consent should be documented. (Evidence level 4, Recommendation grade D.)
\end{abstract}

Statement 2015: We recommend that informed consent for NAAP be obtained from the patient or his/her legal representative according to domestic laws and regulations in a way similar to that for endoscopy procedures. We suggest using alternative methods for vulnerable populations such as elderly patients (weak recommendation, low quality evidence).

\section{Background}

A significant proportion of complications after endoscopy is related to sedation $[41,42]$. In a series of 59 ERCP procedures for which malpractice was alleged, Cotton showed the importance of face-to-face communication between the endoscopist and the patient [134]. Information pertaining to sedation should be provided, including the pros and cons of sedation, with information about alternatives and about the option of unsedated endoscopy.

\section{New information since 2010}

A review of 13 studies ( 3 RCTs), including but not limited to endoscopy, found that patients' recollection and understanding of the medical procedures, risks, and complications is often low, particularly among older individuals [135]. In a study from South Korea, only $56 \%$ of patients who underwent endoscopy under sedation answered that they were aware of the risks of sedatives [136]. The use of interactive multimedia and written material that are easy to read and comprehend increases patient awareness, recollection, and understanding of the consent procedure [135]. For vulnerable populations, it has been proposed that education classes be given to groups of patients with the informed consent procedure provided at the end of the class and before the scheduling of the endoscopic procedure [137]. 
These guidelines from ESGE and ESGENA represent a consensus of best practice based on the available evidence at the time of preparation. They may not apply in all situations and should be interpreted in the light of specific clinical situations and resource availability. Further controlled clinical studies may be needed to clarify aspects of the statements, and revision may be necessary as new data appear. Clinical consideration may justify a course of action at variance to these recommendations. ESGE guidelines are intended to be an educational device to provide information that may assist endoscopists in providing care to patients. They are not rules and should not be construed as establishing a legal standard of care or as encouraging, advocating, requiring, or discouraging any particular treatment.

Competing interests: A. Riphaus has received speaker fees from Fresenius Kabi, Nycomed, Falk Foundation, and Astra Zeneca, and research support from Fresenius Kabi and Oridion.

\section{Institutions}

${ }^{1}$ La Plata, Argentina

2 Department of Medicine, Klinikum Agnes Karll, Laatzen, Germany

Department of Internal Medicine, Division of Gastroenterology and Hepatology, Medical University Graz, Graz, Austria

${ }^{4}$ Gastro Unit, Division of Surgical Gastroenterology, Copenhagen University Hospital, Herlev, Denmark

European Society of Gastroenterology and Endoscopy Nurses and Associates (ESGENA), Scientific Secretary, Ulm, Germany

${ }^{6}$ Endoscopy Unit, Hospital General Universitario de Alicante, Pintor Baeza s/n, Alicante, Spain

Department of Gastroenterology and Hepatology, Cleveland Clinic Lerner College of Medicine of Case Western University, Cleveland, Ohio, USA

${ }^{8}$ Department of Anesthesiology, Benizelion General Hospital, L. Knossou, Heraklion, Crete, Greece

${ }^{9}$ Department of Gastroenterology, Sint Lucas Andreas Ziekenhuis, Amsterdam, The Netherlands

${ }^{10}$ First Department of Internal Medicine and Gastroenterology, Petz Aladar Hospital, Gyor, Vasvari, Hungary

${ }^{11}$ Gastroenterology Department, Nuovo Regina Margherita Hospital, Rome, Italy

12 Department of Gastroenterology, Benizelion General Hospital, L. Knossou, Heraklion, Crete, Greece

\section{References}

1 Baudet J-S, Borque P, Borja $E$ et al. Use of sedation in gastrointestinal endoscopy: a nationwide survey in Spain. Eur J Gastroenterol Hepatol 2009; 21: $882-888$

2 Paspatis GA, Manolaraki MM, Tribonias G et al. Endoscopic sedation in Greece: results from a nationwide survey for the Hellenic Foundation of gastroenterology and nutrition. Dig Liv Dis 2009; 41: 807-811

3 Heuss L, Froehlich F, Beglinger C. Nonanesthesiologist-administered propofol sedation: from the exception to standard practice. Sedation and monitoring trends over 20 years. Endoscopy 2012; 44: 504-511

4 Riphaus A, Macias Gomez C, Deviere J et al. Propofol, the preferred sedation for screening colonoscopy, is underused. Results of an international survey. Dig Liv Dis 2012; 44: 389-392

5 Riphaus A, Geist F, Wehrmann T. Endoscopic sedation and monitoring practice in Germany: re-evaluation from the first nationwide survey 3 years after the implementation of an evidence and consent based national guideline. Z Gastroenterol 2013; 51: 1082 - 1088

6 Dumonceau JM, Riphaus A, Aparicio JR et al. European Society of Gastrointestinal Endoscopy, European Society of Gastroenterology and Endoscopy Nurses and Associates, and the European Society of Anaesthesiology Guideline: Non-anaesthesiologist administration of propofol for GI endoscopy. Eur J Anaesth 2010; 27: 1016-1030

7 Pelosi P. Retraction of endorsement: European Society of Gastrointestinal Endoscopy, European Society of Gastroenterology and Endoscopy Nurses and Associates, and the European Society of Anaesthesiology Guideline: Non-anaesthesiologist administration of propofol for GI endoscopy. Endoscopy 2012; 44: 302

8 Dumonceau JM, Riphaus A, Aparicio JR et al. European Society of Gastrointestinal Endoscopy, European Society of Gastroenterology and Endoscopy Nurses and Associates, and the European Society of Anaes- thesiology Guideline: Non-anesthesiologist administration of propofol for GI endoscopy. Endoscopy 2010; 42: 960-974

9 Atkins $D$, Best $D$, Briss PA et al. Grading quality of evidence and strength of recommendations. BMJ 2004; 328: 1490

10 McQuaid KR, Laine L. A systematic review and meta-analysis of randomized, controlled trials of moderate sedation for routine endoscopic procedures. Gastrointest Endosc 2008; 67: 910-923

11 DeWitt J, LeBlanc J, McHenry L et al. Endoscopic ultrasound-guided fine needle aspiration cytology of solid liver lesions: a large single-center experience. Am J Gastroenterol 2003; 98: 1976-1981

12 Jung $M$, Hofmann C, Kiesslich $R$ et al. Improved sedation in diagnostic and therapeutic ERCP: propofol is an alternative to midazolam. Endoscopy 2000; $32: 233-238$

13 Riphaus A, Stergiou N, Wehrmann T. Sedation with propofol for routine ERCP in high-risk octogenarians: a randomized, controlled study. Am J Gastroenterol 2005; 100: 1957-1963

14 Meining A, Semmler V, Kassem AM et al. The effect of sedation on the quality of upper gastrointestinal endoscopy: an investigator-blinded, randomized study comparing propofol with midazolam. Endoscopy 2007; 39: $345-349$

15 Singh $H$, Poluha $W$, Cheung $M$ et al. Propofol for sedation during colonoscopy. Cochrane Database Syst Rev 2008; 4: CD006268 DOI 10.1002/14651858.CD006268.pub2

16 Rex DK, Deenadayalu VP, Eid E et al. Endoscopist-directed administration of propofol: a worldwide safety experience. Gastroenterology 2009; 137: 1229-1237; quiz 1518-1229

17 Qadeer MA, Vargo JJ, Khandwala F et al. Propofol versus traditional sedative agents for gastrointestinal endoscopy: a meta-analysis. Clin Gastroenterol Hepatol 2005; 3: 1049-1056

18 Wang $D$, Chen $C$, Chen J et al. The use of propofol as a sedative agent in gastrointestinal endoscopy: a meta-analysis. PLoS ONE 2013; 8: e53311

19 Sieg A. bng-Study-Group. Beck S et al. Safety analysis of endoscopist-directed propofol sedation: a prospective, national multicenter study of 24441 patients in German outpatient practices. J Gastroenterol Hepatol 2014; 29: 517-523

20 Frieling T, Heise J, Kreysel C et al. Sedation-associated complications in endoscopy - prospective multicentre survey of 191142 patients. Z Gastroenterol 2013; 51: 568-572

21 Goudra BG, Singh PM, Gouda G et al. Safety of non-anesthesia provideradministered propofol (NAAP) sedation in advanced gastrointestinal endoscopic procedures: comparative meta-analysis of pooled results. Dig Dis Sci 2015; 60: 2612-2627

22 Sethi S, Wadhwa V, Thaker A et al. Propofol versus traditional sedative agents for advanced endoscopic procedures: A meta-analysis. Dig Endosc 2014; 26: $515-524$

23 Bo L-L, Bai Y, Bian J-J et al. Propofol vs traditional sedative agents for endoscopic retrograde cholangiopancreatography: a meta-analysis. World J Gastroenterol 2011; 17: 3538-3543

24 Hassan C, Rex DK, Cooper GS et al. Endoscopist-directed propofol administration versus anesthesiologist assistance for colorectal cancer screening: a cost-effectiveness analysis. Endoscopy 2012; 44: $456-$ 464

25 Dumonceau JM. Nonanesthesiologist administration of propofol: it's all about money. Endoscopy 2012; 44: 453-455

26 Khiani VS, Soulos P, Gancayco J et al. Anesthesiologist involvement in screening colonoscopy: temporal trends and cost implications in the medicare population. Clin Gastroenterol Hepatol 2012; 10: 58 - 64.e51

27 Mehta PP, Vargo JJ, Dumot JA et al. Does anesthesiologist-directed sedation for ERCP improve deep cannulation and complication rates? Dig Dis Sci 2011; 56: $2185-2190$

28 Jover R, Zapater P, Polanía $E$ et al. Modifiable endoscopic factors that influence the adenoma detection rate in colorectal cancer screening colonoscopies. Gastrointest Endosc 2013; 77: 381 - 389.e381

29 Bannert C, Reinhart K, Dunkler D et al. Sedation in screening colonoscopy: impact on quality indicators and complications. Am J Gastroenterol 2012; 107: 1837-1848

30 Amornyotin S, Prakanrattana $U$, Kachintorn $U$ et al. Propofol-based sedation does not increase rate of perforation during colonoscopic procedure. Gastroenterol Insights 2010; 2: e4

31 Bielawska B, Day AG, Lieberman DA et al. Risk factors for early colonoscopic perforation include non-gastroenterologist endoscopists: a multivariable analysis. Clin Gastroenterol Hepatol 2014; 12: 85-92 
32 Okholm C, Hadikhadem T, Andersen LT et al. No increased risk of perforation during colonoscopy in patients undergoing Nurse Administered Propofol Sedation. Scand J Gastroenterol 2013; 48: 1333-1338

33 Adeyemo A, Bannazadeh M, Riggs T et al. Does sedation type affect colonoscopy perforation rates? Dis Colon Rectum 2014; 57: 110 - 114

34 Fatima H, DeWitt J, LeBlanc J et al. Nurse-administered propofol sedation for upper endoscopic ultrasonography. Am J Gastroenterol 2008; 103: $1649-1656$

35 Vargo JJ, Delegge MH, Feld AD et al. Multisociety sedation curriculum for gastrointestinal endoscopy. Gastrointest Endosc 2012; 76: e1 - e25

36 Dumonceau JM, Riphaus A, Beilenhoff $U$ et al. European curriculum for sedation training in gastrointestinal endoscopy: position statement of the European Society of Gastrointestinal Endoscopy (ESGE) and European Society of Gastroenterology and Endoscopy Nurses and Associates (ESGENA). Endoscopy 2013; 45: 496-504

37 Igea F, Casellas JA, González-Huix F et al. Sedation for gastrointestinal endoscopy. Endoscopy 2014; 46: $720-731$

38 Jensen JT, Vilmann P, Horsted T et al. Nurse-administered propofol sedation for endoscopy: a risk analysis during an implementation phase. Endoscopy 2011; 43: 716-722

39 Slagelse C, Vilmann P, Hornslet P et al. Nurse-administered propofol sedation for gastrointestinal endoscopic procedures: first Nordic results from implementation of a structured training program. Scand J Gastroenterol 2011; 46: 1503-1509

40 Schilling $D$, Leicht $K$, Beilenhoff $U$ et al. Impact of S3 training courses "Sedation and Emergency Management in Endoscopy for Endoscopy Nurses and Assisting Personnel" on the process and structure quality in gastroenterological endoscopy in practices and clinics - results of a nationwide survey. Z Gastroenterol 2013; 51: 619-627

41 Quine MA, Bell GD, McCloy RF et al. Prospective audit of upper gastrointestinal endoscopy in two regions of England: safety, staffing, and sedation methods. Gut 1995; 36: $462-667$

42 Eckardt VF, Kanzler G, Schmitt T et al. Complications and adverse effects of colonoscopy with selective sedation. Gastrointest Endosc 1999; 49: $560-565$

43 Bhananker SM, Posner KL, Cheney FW et al. Injury and liability associated with monitored anesthesia care: a closed claims analysis. Anesthesiology 2006; 104: 228-234

44 Gupta A. Preoperative screening and risk assessment in the ambulatory surgery patient. Curr Opin Anaesthesiol 2009; 22: 705-711

45 Mallampati SR, Gatt SP, Gugino LD et al. A clinical sign to predict difficult tracheal intubation: a prospective study. Can Anaesth Soc J 1985 32: $429-434$

46 American Society of Anesthesiologists. Physical Status Classification System.http://www.asahq.org/resources/clinical-information/asaphysical-status-classification-system Accessed: May 1, 2015

47 American Society of Anesthesiologists Task Force on Sedation and Analgesia by Non-Anesthesiologists. Practice guidelines for sedation and analgesia by non-anesthesiologists. Anesthesiology 2002; 96: 10041017

48 Enestvedt BK, Eisen GM, Holub J et al. Is the American Society of Anesthesiologists classification useful in risk stratification for endoscopic procedures? Gastrointest Endosc 2013; 77: 464 - 471

49 Dietrich CG, Kottmann T, Diedrich A et al. Sedation-associated complications in endoscopy are not reduced significantly by implementation of the German S-3-guideline and occur in a severe manner only in patients with ASA class III and higher. Scand J Gastroenterol 2013; 48: $1082-1087$

50 Friedrich K, Stremmel W, Sieg A. Endoscopist-administered propofol sedation is safe - a prospective evaluation of 10,000 patients in an outpatient practice. J Gastrointest Liver Dis 2012; 21: 259-263

51 Friedrich-Rust $M$, Welte $M$, Welte $C$ et al. Capnographic monitoring of propofol-based sedation during colonoscopy. Endoscopy 2014; 46: $236-244$

52 Mehta PP, Kochhar G, Kalra S et al. Can a validated sleep apnea scoring system predict cardiopulmonary events using propofol sedation for routine EGD or colonoscopy? A prospective cohort study Gastrointest Endosc 2014; 79: 436-444

53 Kerker A, Hardt C, Schlief H-E et al. Combined sedation with midazo$\mathrm{lam} /$ propofol for gastrointestinal endoscopy in elderly patients. BMC Gastroenterol 2010; 10: 11

54 Martínez JF, Aparicio JR, Compañy L et al. Safety of continuous propofol sedation for endoscopic procedures in elderly patients. Rev Esp Enferm Dig 2011; 103: $76-82$
55 Park TY, Choi JS, Oh H-C et al. Assessment of safety of non-anesthesiologist-assisted endoscopic retrograde cholangiopancreatography based on performance status in elderly patients. J Gastroenterol Hepatol 2014; 29: $1943-1948$

56 Horiuchi A, Nakayama Y, Tanaka $N$ et al. Propofol sedation for endoscopic procedures in patients 90 years of age and older. Digestion 2008; 78: $20-23$

57 Coté GA, Hovis RM, Ansstas MA et al. Incidence of sedation-related complications with propofol use during advanced endoscopic procedures. Clin Gastroenterol Hepatol 2010; 8: 137-142

58 Wani S, Azar R, Hovis CE et al. Obesity as a risk factor for sedation-related complications during propofol-mediated sedation for advanced endoscopic procedures. Gastrointest Endosc 2011; 74: 1238 - 1247

59 Friedman M, Tanyeri H, La Rosa $M$ et al. Clinical predictors of obstructive sleep apnea. Laryngoscope 1999; 109: 1901 - 1907

60 Deng $L$, $L i$ C-L, Ge S-J et al. STOP questionnaire to screen for hypoxemia in deep sedation for young and middle-aged colonoscopy. Dig Endosc 2012; 24: $255-258$

61 Boese ML, Ransom RK, Roadfuss RJ et al. Utility of the Berlin Questionnaire to screen for obstructive sleep apnea among patients receiving intravenous sedation for colonoscopy. AANA J 2014; 82: 38 - 45

62 Qaseem A, Dallas P, Owens DK et al. Diagnosis of obstructive sleep apnea in adults: a clinical practice guideline from the American College of Physicians. Ann Intern Med 2014; 161: 210-220

63 Chung F, Yegneswaran B, Liao $P$ et al. STOP questionnaire: a tool to screen patients for obstructive sleep apnea. Anesthesiology 2008 108: $812-821$

64 Chung F, Yang Y, Liao P. Predictive performance of the STOP-Bang score for identifying obstructive sleep apnea in obese patients. Obes Surg 2013; 23: 2050-2057

65 Tsai HC, Lin YC, Ko CL et al. Propofol versus midazolam for upper gastrointestinal endoscopy in cirrhotic patients: a meta-analysis of randomized controlled trials. PLoS One 2015; 10: e0117585

66 Riphaus A, Wehrmann T, Weber B et al. S3 Guideline: Sedation for gastrointestinal endoscopy 2008. Endoscopy 2009; 41: 787-815

67 Lichtenstein DR, Jagannath S, Baron TH et al. Standards of Practice Committee of the American Society for Gastrointestinal Endoscopy. Sedation and anesthesia in GI endoscopy. Gastrointest Endosc 2008; 68 : $815-826$

68 Riphaus A, Wehrmann T, Hausmann J et al. S3-guidelines "sedation in gastrointestinal endoscopy" 2014 (AWMF register no. 021/014) [in German]. Z Gastroenterol 2015; 53: 802 - 842

69 Walder B, Riphaus A, Dumonceau JM. Reply to Külling et al. Endoscopy 2011; 43: 637-638

70 Smith MR, Bell GD, Fulton B et al. A comparison of winged steel needles and Teflon cannulas in maintaining intravenous access during gastrointestinal endoscopy. Gastrointest Endosc 1993; 39: 33-36

71 Rozario L, Sloper D, Sheridan MJ. Supplemental oxygen during moderate sedation and the occurrence of clinically significant desaturation during endoscopic procedures. Gastroenterol Nurs 2008; 31: 281 - 285

72 Patterson KW, Noonan N, Keeling NW et al. Hypoxemia during outpatient gastrointestinal endoscopy: the effects of sedation and supplemental oxygen. J Clin Anesth 1995; 7: $136-140$

73 Iwao $T$, Toyonaga A, Shigemori $H$ et al. Supplemental oxygen during endoscopic variceal ligation: effects on arterial oxygenation and cardiac arrhythmia. Am J Gastroenterol 1995; 90: 2186-2190

74 Haines DJ, Bibbey D, Green JR. Does nasal oxygen reduce the cardiorespiratory problems experienced by elderly patients undergoing endoscopic retrograde cholangiopancreatography? Gut 1992; 33: 973-975

75 Gross JB, Long WB. Nasal oxygen alleviates hypoxemia in colonoscopy patients sedated with midazolam and meperidine. Gastrointest Endosc 1990; 36: 26-29

76 Crantock $L$, Cowen $A E$, Ward $M$ et al. Supplemental low flow oxygen prevents hypoxia during endoscopic cholangiopancreatography. Gastrointest Endosc 1992; 38: 418-420

77 Bowling TE, Hadjiminas CL, Polson RJ et al. Effects of supplemental oxygen on cardiac rhythm during upper gastrointestinal endoscopy: a randomised controlled double blind trial. Gut 1993; 34: 1492-1497

78 Bell GD, Quine A, Antrobus JH et al. Upper gastrointestinal endoscopy: a prospective randomized study comparing continuous supplemental oxygen via the nasal or oral route. Gastrointest Endosc 1992; 38 : $319-325$

79 Sharma VK, Nguyen CC, Crowell MD et al. A national study of cardiopulmonary unplanned events after GI endoscopy. Gastrointest Endosc 2007; 66: 27-34 
80 Froehlich F, Harris JK, Wietlisbach V et al. Current sedation and monitoring practice for colonoscopy: an International Observational Study (EPAGE). Endoscopy 2006; 38: $461-469$

81 Riphaus A, Rabofski M, Wehrmann T. Endoscopic sedation and monitoring practice in Germany: results from the first nationwide survey. Z Gastroenterol 2010; 48: $392-397$

82 Vargo JJ, Zuccaro G, Dumot JA et al. Automated graphic assessment of respiratory activity is superior to pulse oximetry and visual assessment for the detection of early respiratory depression during therapeutic upper endoscopy. Gastrointest Endosc 2002; 55: 826-831

83 Qadeer MA, Rocio Lopez A, Dumot JA et al. Hypoxemia during moderate sedation for gastrointestinal endoscopy: causes and associations. Digestion 2011; 84: $37-45$

84 Qadeer MA, Vargo JJ, Dumot JA et al. Capnographic monitoring of respiratory activity improves safety of sedation for endoscopic cholangiopancreatography and ultrasonography. Gastroenterology 2009; 136: 1568 -1576; quiz 1819-1520

85 Lightdale JR, Goldmann DA, Feldman HA et al. Microstream capnography improves patient monitoring during moderate sedation: a randomized, controlled trial. Pediatrics 2006; 117: e1170-e1178

86 American Society of Anesthesiologists Committee. ASA Standards for 2011 - Capnography. Available from: http://www.capnography.com Accessed: April 28, 2015

87 Statement by the American Society of Gastrointestinal Endoscopy, American College of Gastroenterology and the American Gastroenterological Association. Universal adoption of capnography for moderate sedation in adults undergoing upper endoscopy and colonoscopy has not been shown to improve patient safety or clinical outcomes and significantly increases costs for moderate sedation. Available from: http://www.asge.org/assets/0/71542/71544/90dc9b63-593d-48a9bec1-9f0ab3ce946a.pdf Accessed: April 28, 2015

88 Beitz A, Riphaus A, Meining A et al. Capnographic monitoring reduces the incidence of arterial oxygen desaturation and hypoxemia during propofol sedation for colonoscopy: a randomized, controlled study (ColoCap Study). Am J Gastroenterol 2012; 107: 1205-1212

89 Slagelse C, Vilmann $P$, Hornslet $P$ et al. The role of capnography in endoscopy patients undergoing nurse-administered propofol sedation: a randomized study. Scand J Gastroenterol 2013; 48: 1222 - 1230

90 Wehrmann T, Grotkamp J, Stergiou N et al. Electroencephalogram monitoring facilitates sedation with propofol for routine ERCP: a randomized, controlled trial. Gastrointest Endosc 2002; 56: 817-824

91 Paspatis GA, Chainaki I, Manolaraki MM et al. Efficacy of bispectral index monitoring as an adjunct to propofol deep sedation for ERCP: a randomized controlled trial. Endoscopy 2009; 41: 1046-1051

92 Imagawa A, Fujiki S, Kawahara Y et al. Satisfaction with bispectral index monitoring of propofol-mediated sedation during endoscopic submucosal dissection: a prospective, randomized study. Endoscopy 2008; 40: 905 - 909

93 Drake LM, Chen SC, Rex DK. Efficacy of bispectral monitoring as an adjunct to nurse-administered propofol sedation for colonoscopy: a randomized controlled trial. Am J Gastroenterol 2006; 101: 2003-2007

94 von Delius S, Salletmaier $H$, Meining A et al. Bispectral index monitoring of midazolam and propofol sedation during endoscopic retrograde cholangiopancreatography: a randomized clinical trial (the EndoBIS study). Endoscopy 2012; 44: 258-264

95 Jang SY, Park HG, Jung MK et al. Bispectral index monitoring as an adjunct to nurse-administered combined sedation during endoscopic retrograde cholangiopancreatography. World J Gastroenterol 2012; 18: $6284-6289$

$96 \mathrm{Yu} Y H$, Han D-S, Kim HS et al. Efficacy of bispectral index monitoring during balanced propofol sedation for colonoscopy: a prospective, randomized controlled trial. Dig Dis Sci 2013; 58: 3576-3583

97 Park WY, Shin Y-S, Lee SK et al. Bispectral index monitoring during anesthesiologist-directed propofol and remifentanil sedation for endoscopic submucosal dissection: a prospective randomized controlled trial. Yonsei Med J 2014; 55: 1421 - 1429

98 American Society of Anesthesiologists Task Force on Preanesthesia Evaluation. Practice advisory for preanesthesia evaluation: a report by the American Society of Anesthesiologists Task Force on Preanesthesia Evaluation. Anesthesiology 2002; 96: 485-496

99 Ely EW, Truman B, Shintani A et al. Monitoring sedation status over time in ICU patients: reliability and validity of the Richmond Agitation-Sedation Scale (RASS). JAMA 2003; 289: 2983-2991

100 Chawla S, Katz A, Attar BM et al. Endoscopic retrograde cholangiopancreatography under moderate sedation and factors predicting need for anesthesiologist directed sedation: A county hospital experience. World J Gastrointest Endosc 2013; 5: 160-164

101 Cotton PB. Income and outcome metrics for the objective evaluation of ERCP and alternative methods. Gastrointest Endosc 2002; 56: $\mathrm{S} 283-\mathrm{S} 290$

102 Wang D, Wang S, Chen J et al. Propofol combined with traditional sedative agents versus propofol- alone sedation for gastrointestinal endoscopy: a meta-analysis. Scand J Gastroenterol 2013; 48: 101 110

103 Horiuchi A, Nakayama Y, Fujii $H$ et al. Psychomotor recovery and blood propofol level in colonoscopy when using propofol sedation. Gastrointest Endosc 2012; 75: 506-512

104 Horiuchi A, Nakayama Y, Kajiyama $M$ et al. Safety and effectiveness of propofol sedation during and after outpatient colonoscopy. World J Gastroenterol 2012; 18: 3420-3425

105 Paspatis GA, Charoniti I, Manolaraki M et al. Synergistic sedation with oral midazolam as a premedication and intravenous propofol versus intravenous propofol alone in upper gastrointestinal endoscopies in children: a prospective, randomized study. J Pediatr Gastroenterol Nutr 2006; 43: 195 - 199

106 Paspatis G, Manolaraki M, Vardas E et al. Deep sedation for endoscopic retrograde cholangiopancreatography: intravenous propofol alone versus intravenous propofol with oral midazolam premedication. Endoscopy 2008; 40: 308-313

107 Crepeau T, Poincloux L, Bonny $C$ et al. Significance of patient-controlled sedation during colonoscopy. Results from a prospective randomized controlled study. Gastroenterol Clin Biol 2005; 29: 1090 1096

108 Heuss LT, Drewe J, Schnieper P et al. Patient-controlled versus nurseadministered sedation with propofol during colonoscopy. A prospective randomized trial. Am J Gastroenterol 2004; 99: 511 - 518

109 Pambianco DJ, Vargo JJ, Pruitt RE et al. Computer-assisted personalized sedation for upper endoscopy and colonoscopy: a comparative, multicenter randomized study. Gastrointest Endosc 2011; 73: 765 772

110 Dumonceau JM, Riphaus A, Wehrmann T. Preparation, sedation, and monitoring. Endoscopy 2012; 44: 403 - 407

111 Mazanikov M, Udd M, Kylänpää $L$ et al. A randomized comparison of target-controlled propofol infusion and patient-controlled sedation during ERCP. Endoscopy 2013; 45: 915 - 919

112 Mazanikov M, Udd M, Kylänpää $L$ et al. Patient-controlled sedation with propofol and remifentanil for ERCP: a randomized, controlled study. Gastrointest Endosc 2011; 73: 260-266

113 Fanti L, Gemma M, Agostoni $M$ et al. Target Controlled Infusion for non-anaesthesiologist propofol sedation during gastrointestinal endoscopy: The first double blind randomized controlled trial. Dig Liver Dis 2015; 47: 566-571

$114 X u C-X$, Chen X, Jia $Y$ et al. Stepwise sedation for elderly patients with mild/moderate COPD during upper gastrointestinal endoscopy. World J Gastroenterol 2013; 19: 4791 -4798

115 Wang MC, Zhang $L Y$, Zhang YL et al. Effect of music in endoscopy procedures: systematic review and meta-analysis of randomized controlled trials. Pain Med 2014; 15: 1786 -1794

116 Evans LT, Saberi S, Kim HM et al. Pharyngeal anesthesia during sedated EGDs: is "the spray" beneficial? A meta-analysis and systematic review Gastrointest Endosc 2006; 63: 761 - 766

117 de la Morena F, Santander C, Esteban C et al. Usefulness of applying lidocaine in esophagogastroduodenoscopy performed under sedation with propofol. World J Gastrointest Endosc 2013; 5: 231 -239

118 Heuss LT, Hanhart A, Dell-Kuster S et al. Propofol sedation alone or in combination with pharyngeal lidocaine anesthesia for routine upper GI endoscopy: a randomized, double-blind, placebo-controlled, noninferiority trial. Gastrointest Endosc 2011; 74: 1207-1214

119 Tallis GF, Ryan GM, Lambert SB et al. Evidence of patient-to-patient transmission of hepatitis $C$ virus through contaminated intravenous anaesthetic ampoules. J Viral Hepatitis 2003; 10: 234-239

120 Fukada T, Ozaki M. Microbial growth in propofol formulations with disodium edetate and the influence of venous access system dead space. Anaesthesia 2007; 62: 575-580

121 Picard $P$, Tramèr MR. Prevention of pain on injection with propofol: a quantitative systematic review. Anesth Analg 2000; 90: 963-969

122 Müller M, Wehrmann T, Eckardt AJ. Prospective evaluation of the routine use of a nasopharyngeal airway (Wendl Tube) during endoscopic propofol-based sedation. Digestion 2014; 89: 247-252 
123 Molina-Infante J, Arias A, Vara-Brenes D et al. Propofol administration is safe in adult eosinophilic esophagitis patients sensitized to egg, soy, or peanut. Allergy 2014; 69: 388-394

124 Newman DH, Azer MM, Pitetti RD et al. When is a patient safe for discharge after procedural sedation? The timing of adverse effect events in 1367 pediatric procedural sedations Ann Emerg Med 2003; 42: 627-635

125 Chung F, Chan VW, Ong D. A post-anesthetic discharge scoring system for home readiness after ambulatory surgery. J Clin Anesth 1995; 7: 500-506

126 Aldrete JA. Modifications to the postanesthesia score for use in ambulatory surgery. J Perianesth Nurs 1998; 13: 148-155

127 Amornyotin S, Chalayonnavin W, Kongphlay S. Recovery pattern and home-readiness after ambulatory gastrointestinal endoscopy. J Med Assoc Thai 2007; 90: $2352-2358$

128 Trevisani L, Cifalà V, Gilli G et al. Post-Anaesthetic Discharge Scoring System to assess patient recovery and discharge after colonoscopy. World J Gastrointest Endosc 2013; 5: 502 - 507

129 Willey J, Vargo JJ, Connor JT et al. Quantitative assessment of psychomotor recovery after sedation and analgesia for outpatient EGD. Gastrointest Endosc 2002; 56: 810-816

130 Horiuchi A, Nakayama Y, Hidaka $N$ et al. Low-dose propofol sedation for diagnostic esophagogastroduodenoscopy: results in 10,662 adults. Am J Gastroenterol 2009; 104: 1650-1655

131 Watkins TJ, Bonds RL, Hodges K et al. Evaluation of postprocedure cognitive function using 3 distinct standard sedation regimens for endoscopic procedures. AANA J 2014; 82: 133-139
132 Pitetti R, Davis PJ, Redlinger $R$ et al. Effect on hospital-wide sedation practices after implementation of the 2001 JCAHO procedural sedation and analgesia guidelines. Arch Ped Adol Med 2006; 160: 211 216

133 Aisenberg J, Cohen LB, Piorkowski JD. Propofol use under the direction of trained gastroenterologists: an analysis of the medicolegal implications. Am J Gastroenterol 2007; 102: 707 - 713

134 Cotton PB. Analysis of 59 ERCP lawsuits; mainly about indications. Gastrointest Endosc 2006; 63: 378-382

135 Sherlock A, Brownie S. Patients' recollection and understanding of informed consent: a literature review. ANZ J Surg 2014; 84: 207-210

136 Song JH, Yoon HS, Min BH et al. Acceptance and understanding of the informed consent procedure prior to gastrointestinal endoscopy by patients: a single-center experience in Korea. Korean J Intern Med 2010; $25: 36-43$

137 Siao D, Sewell JL, Day LW. Assessment of delivery methods used in the informed consent process at a safety-net hospital. Gastrointest Endosc 2014; 80: $61-68$

138 Adler DG, Kawa C, Hilden K et al. Nurse-administered propofol sedation is safe for patients with obstructive sleep apnea undergoing routine endoscopy: a pilot study. Dig Dis Sci 2011; 56: 2666 - 2671

139 Corso RM, Piraccini E, Agnoletti V et al. Clinical use of the STOP-BANC questionnaire in patients undergoing sedation for endoscopic procedures. Minerva Anestesiol 2012; 78: 109-110

140 Coté GA, Hovis CE, Hovis RM et al. A screening instrument for sleep apnea predicts airway maneuvers in patients undergoing advanced endoscopic procedures. Clin Gastroenterol Hepatol 2010; 8: 660 $665 . e 661$ 